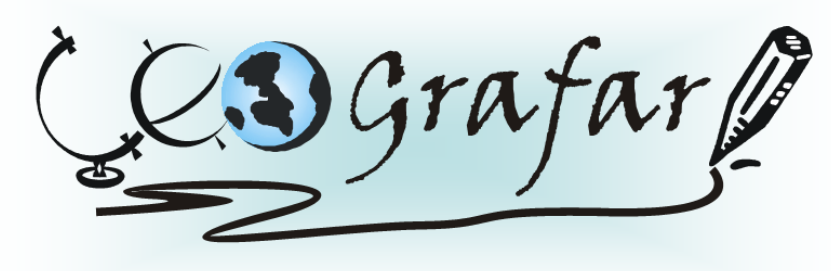

Revista Eletrônica do Programa de Pós-Graduação em Geografia - UFPR

\title{
DESVENDANDO OS TERROIRS AGROECOLÓGICOS DE RIO BRANCO DO SUL- PR: UMA ABORDAGEM GEO-SÓCIO-AGRONÔMICA DA PAISAGEM RURAL E DO DIAGNÓSTICO PARTICIPATIVO DO TERRITÓRIO
}

\author{
Nicolas Floriani ${ }^{1}$ \\ Dimas Floriani $^{2}$ \\ Leonardo José Cordeiro Santos ${ }^{3}$ \\ Celina Wisniewiski ${ }^{4}$ \\ Alfio Brandenburg ${ }^{5}$
}

\begin{abstract}
RESUMO - O texto discute o diagnóstico vernacular das paisagens por agricultores ecológicos de Rio Branco do Sul-PR. Parte-se da discussão da necessidade de uma nova abordagem espacial das práticas produtivas com base na integração de idéias como o Sistema de Práticas e os Geossistemas - configurados nos Terroirs (metodologia de geógrafos e agrônomos tropicalistas pouco estudada no Brasil). O diagnóstico participativo do território insere-se no contexto do diálogo do saberes enquanto reflexão capaz de engendrar um pensamento complexo acerca das relações sociedade-natureza por buscar incluir em seu referencial teórico-metodológico os saberes produzidos e operados localmente. Aplicada ao estudo da percepção e representação vernaculares das potencialidades e fragilidades das terras e da paisagem, a problemática do manejo sustentável dos recursos naturais é inserida na discussão das classificações e avaliações populares das paisagens e de seus elementos constituintes. Tal abordagem pode subsidiar projetos de desenvolvimento territorial rural condizentes com as realidades socioambientais locais.
\end{abstract}

Palavras-chave: terroirs, agroecologia, saberes locais, diagnóstico participativo.

\begin{abstract}
The text discusses the vernacular diagnostic of landscapes by agroecologicals farmers from Rio Branco do Sul-PR. The dialogue of knowledges appears as a mean to generate an understanding about the complexity of the society-nature relationship. Therefore, it is important to include in these theoretical and methodological references the local knowledge of farmers about their territory of agricultural production. The methodological support arise in the need for a new spatial approach of productive practices based on the integration of ideas like Pratices System and Geosystems - set in Terroirs - (methodology of tropicalist geographers and agronomists little studied in Brazil). Applied to the study of farmer's perception and representation about the capabilities and limitations of the soils, the issue of sustainable management of natural resources is included in this discussion, signing the text on current issues such as ethnoconservation, which stand in the traditional local hierarchy of environments. This approach could subsidize rural development projects consistent with the local environmental and social realities.
\end{abstract}

Key-words: terroirs, agroecology, local knowledges, participatory appraisal

\footnotetext{
${ }^{1}$ Eng. Agrônomo, Doutorado em Meio Ambiente e Desenvolvimento (UFPR), Prof. Visitante do Programa de Mestrado em Gestão do Território, Universidade Estadual de Ponta Grossa (UEPG), nicolas@ uepg.br

${ }^{2}$ Sociólogo, Doutorado em Ciências Sociais (UCL-Bel), Prof. Titular do Depto. de Ciências Sociais da Universidade Federal do Paraná (UFPR), floriani@ufpr.br

${ }^{3}$ Geógrafo, Doutorado em Geografia (USP), Prof. Adjunto do Depto. Geografia da Universidade Federal do Paraná (UFPR), santos@ufpr.br

${ }^{4}$ Eng. Florestal, Doutorado em Engenharia Florestal (UFPR), Profa. Adjunta do Depto. de Solos da Unversidade Federal do Paraná (UFPR), cewisni@ufpr.br

5 Eng. Agrônomo, Doutorado em Ciências Sociais (Unicamp), Prof. Adjunto do Depto. Ciências Sociais da Universidade Federal do Paraná (UFPR), alfio@onda.com.br
} 


\section{INTRODUÇÃO}

A questão da gestão e manejo dos recursos naturais requer uma abordagem complexa dos fenômenos espaciais, necessitando-se de uma leitura antropossocial das paisagens a fim de interpretar e lançar hipóteses sobre o entendimento (percepções e representações) que os agricultores possuem acerca dos elementos geobiocenóticos constituintes das paisagens rurais.

Pesquisas no âmbito da gestão e manejo dos recursos naturais em áreas rurais têm sido realizadas tradicionalmente pela Geografia Regional Tropicalista desde os anos 50, especialmente nas comunidades rurais africanas. Por sua vez, a Agronomia tem se aproximado tardiamente da problemática sócioambiental da gestão dos recursos naturais. Da revisão de seus preceitos científicos a partir dos 80 do século $\mathrm{XX}$, passada a euforia da modernização da agricultura, é forçada a se abrir à abordagem espacial (territorializada) das práticas produtivas.

Da junção da paisagem física com a cultural derivou nossa interpretação da Paisagem Rural: a concepção dos agricultores a respeito da natureza (suas matrizes cognitivas) aparece em seus discursos e em suas práticas agrícolas (as marcas) na Paisagem, da qual emergem entidades espaciais que dão identidade ao território da exploração agrícola familiar.

Nesse sentido, tratou-se de identificar e caracterizar as marcas e as matrizes que configuram as paisagens rurais, transformadas pelos diversos tipos de agricultura familiar, isto é, cabendo decifrar os códigos ecológicos desses agricultores - resgatando o termo utilizado por Blanc-Pamard (1986).

Não obstante, desvendar as múltiplas dimensões da paisagem torna-se um objetivo audacioso que só pode ser concebido a partir de um projeto de estudo interdisciplinar. Nesse sentido, a investigação das dimensões sociais (das representações e percepções de natureza) e físicas (a estrutura e o funcionamento dos geossistemas) requer uma abordagem multidimensional da paisagem, isto é, requer uma abordagem geo-sócio-agronômica da paisagem rural que permita captar em sua matriz as diversas formas da relação dinâmica entre sociedade e natureza. 
Em termos práticos, nossa pesquisa interdisciplinar ${ }^{6}$ previu em seu referencial metodológico a interpretação e a comparação de dois discursos: a do pesquisador (do cientista que constrói uma teia lógica de relações acerca das relações entre as práticas agrícolas e os outros elementos da paisagem) e aquele dos agricultores ecológicos de Rio Branco do Sul que possuem um entendimento operacional e estético, geralmente distinto, a cerca das dinâmicas produtivas da natureza. Uma sugestão de interpretação da complexidade dos sistemas ambientais foi pensada por Georges Bertrand - o GTP (Geossistema, Território e Percepção). Com isso, ele nos fornece subsídios ao estudo dos Terroirs, cuja particularidade reside segundo Jean-Pierre Deffontaines na interpretação agronômica do funcionamento da paisagem, isto é na abordagem espacial das práticas agrícolas.

Carregados de subjetividades e simbolismos, os terroirs refletem as paisagens rurais desenhadas conforme os projetos individuais e coletivos sintetizados nas ações dos movimentos sociais agroecológicos. Os entendimentos (concepções) de natureza derivam de um mosaico de influências que combinam diferentes tipos de saberes sobre a paisagem rural e que são filtrados e reelaborados conforme os anseios e projetos dos agricultores, tendo-se em vista que a propriedade familiar é o lugar onde reside a autonomia do(a) agricultor(a) em relação ao mundo do sistema racional.

Ora, trata-se interpretar a configuração de territórios agroecológicos que se configuram como lugares alternativos aos grandes espaços "vazios" produtivos valorizados sazonalmente pelo mercado e pensados de acordo ao projeto de desenvolvimento modernizador para o meio rural.

Por fim, o recorte espacial das práticas agrícolas, ou seja, entendimento do funcionamento (organização) das relações entre as agriculturas e a natureza passa pelo estudo das representações e percepções do espaço, o que foi incluído em nosso referencial teóricometodológico dos Terroirs, inserindo tal análise no contexto do diálogo de saberes e da gestão coletiva dos recursos naturais.

\footnotetext{
${ }^{6}$ Programa de doutorado em Meio Ambiente e Desenvolvimento (MADE-UFPR) possui como metodologia de pesquisa o trabalho coletivo interdisciplinar que parte de uma problemática sócioambiental e área geográfica comuns na Região Metropolitana de Curitiba e Litoral.
} 


\section{O CONHECIMENTO DAS PRÁTICAS: A SÍNTESE DAS AÇÕES COLETIVAS NA PRODUÇÃO DA PAISAGEM}

Com o surgimento de novos problemas socioambientais advindos do seio do modelo modernizador da agricultura, novos atores rurais começam a questionar e demandar soluções aos agrônomos com cujas ferramentas científicas e técnicas se mostram incapazes de responder ou oferecer alternativas às populações excluídas e aos ambientes degradados pelo processo modernizador.

Com a crise do paradigma científico moderno, os esquemas de avaliações clássicas das potencialidades das terras mostram-se combalidos em seus fundamentos ${ }^{7}$. Os agrônomos devem agora abrir os olhos ao espaço que se torna uma dimensão primordial para pensar as ações sobre a parcela e a exploração agrícola, ou seja, é necessário, de acordo a Deffontaines (2006) "que o agrônomo deixe a idéia de parcela e de potencialidade desenvolvida pela agronomia hegemônica (do tipo "façon-de-produir"), para adotar uma visão mais global da exploração, deslocando do centro da análise a estrutura do sistema produtivo para destacar o sistema de práticas, situando-o no espaço onde ele é desenvolvido.

É preciso, então, abrir a Agronomia à complexidade do território. Para tanto, mais que nunca, é necessário apreender a estrutura e o funcionamento dos sistemas territoriais em todas as escalas de espaço e de tempo. Assim, a paisagem e a abordagem espacial das práticas agrícolas estão no centro de uma nova forma de ver o campo cultivado. O campo, espaço definido pela identidade das práticas, faceta de uma paisagem percebida e vivida por um grupo social, torna-se o centro da análise geo-sócio-agronômica ${ }^{8}$.

Assim como a noção de paisagem, outras idéias são revisitadas na superação dos pressupostos teóricos e metodológicos que guiam o percurso analítico da ciência moderna. $\mathrm{O}$ contexto de desordem em que se encontra o paradigma clássico aponta ao mesmo tempo para a possibilidade da configuração de uma nova ordem científica emergente a ser catalizada a

\footnotetext{
${ }^{7}$ Para Bertrand e Bertrand (2002), a parcela e o sistema de cultivos - lugar das técnicas e unidade funcional de base da agronomia moderna - não são mais que outros elementos de um mosaico geográfico fragmentado e instável, submetido a múltiplas estratégias econômicas e valores culturais contraditórios.

${ }^{8}$ Esse neologismo foi sugerido em conversa com o Prof. Dimas Floriani, coordenador da Linha de pesquisa "Epistemologia Ambiental" do MADE, grande incentivador de minhas incursões pelas ciências sociais. Representa uma tentativa de reconstrução do termo géo-agronomie (de Jean-Pierre Deffontaines) de acordo a um novo referencial teórico-metodológico, resultante do apoio das ciências sociais na discussão da paisagem, isto é, enquanto categoria teórica integradora da sociologia com a geografia e agronomia.
} 
partir do esforço da síntese que há de se operar entre as ciências sociais e as ciências da natureza. Nesta síntese, a distinção hierárquica entre conhecimento científico e conhecimento vulgar tenderá a desaparecer e a prática será o fazer e o dizer da Filosofia das Práticas ${ }^{9}$ (SOUSA SANTOS, 2005, p. 20).

Não obstante, o interesse de se afirmar sobre bases científicas, fez com que uma certa dimensão da pesquisa científica tenha desaparecido e com ela a principal possibilidade de articulação com os saberes populares. Contudo, levando-se em conta a similaridade entre esses esquemas cognitivos classificatórios, os cientistas e o homem comum poderiam encontrar seu ponto de reencontro ${ }^{10}$ (CHATELIN et al, 1986, p.11-13).

Sabemos de Claval (2005, p. 19) que os saberes vernaculares são indissociáveis das formas apreendidas, mobilizadas para explorar o ambiente, produzir as ferramentas $\mathrm{e}$ equipamentos demandados pelo indivíduo, a célula familiar ou o grupo, inserindo-se nas redes existentes das relações sociais. A maioria dos traços de geografias vernaculares organizadas pelas culturas onde a oralidade joga uma importante função não é dissociada, nem tampouco dissociável, de suas práticas produtivas.

Assim a 'ressubjetivação' do conhecimento científico pode traduzir-se num saber vulgar e prático com o qual, no quotidiano, são orientadas nossas ações e é dado sentido a nossa vida. Essa ressubjetivação potencializaria a ciência emergente ao reconhecer no senso comum uma visão do mundo assente na ação (SOUSA SANTOS, 2005, p.88).

Partindo do enfoque das representações geográficas busca-se, então, uma leitura interiorizada sob a ótica do cotidiano vivido pelos grupos humanos, levando à compreensão dos sistemas de valorização e territorialidade correspondentes, e, por meio das subjetividades, viabiliza a seleção de elementos importantes para o estabelecimento das regiões. Nesse sentido, os estudos regionais devem evidenciar muito mais que os recortes apresentados, pois

\footnotetext{
${ }^{9}$ Nesse contexto de crise ambiental e do paradigma da ciência agronômica moderna, emerge um novo entendimento da dualidade "técnica versus práticas" (ou lógicas de ação) permitindo pensar uma terceira perspectiva agronômica, ainda em fase de construção: se por um lado, as técnicas podem ser analisadas, elaboradas, testadas independentemente daqueles que as utilizam, as práticas não podem ser estudadas sem se levar em consideração as condições nas quais agem os agricultores, sem uma análise do contexto social, econômico e ecológico da ação (ALMEIDA, 2000, p. 04).

${ }^{10}$ Da comparação entre os conhecimentos vernacular e o científico, Chatelin et al (1986 p.06), citando Barrau, destaca que "não há fundamentalmente diferenças de princípios entre conhecimentos populares e conhecimentos científicos da natureza": a grande pluralidade dos métodos e saberes particulares mostra que o processo cognitivo é o mesmo em todos os casos, isto é, as classificações populares se ajustam às taxonomias científicas. Concretamente, o autor faz inferência às classificações dos elementos naturais pelas populações locais tradicionais de países tropicais, constatando que em algumas classificações há $61 \%$ de correspondência entre informações populares e informações científicas.
} 
ao descobrir os homens e o sentido que atribuem ao lugar, descobrirão as comunidades e as territorialidades, desvendando as ideologias espaciais, muitas vezes remetendo ao cerne de numerosos conflitos existentes no mundo contemporâneo (KOZEL, 2002, p. 216).

Concebida como 'marca e matriz' - utilizando a expressão de Augustin Berque - das ações humanas sobre o espaço, a paisagem segundo Deffontaines (2006) é entendida pelo agricultor como ato de suas práticas. Nesse sentido, o agricultor é também produtor de formas. E se o agricultor produz formas, há também uma linguagem visual da agricultura que resulta, mais que dos processos técnicos de produção, da maneira do agricultor pensar sua atividade e a sua relação com o meio. É aí que se concretiza a independência e autonomia do agricultor em relação ao mundo do sistema racional.

Esse reencontro das dimensões materiais e imateriais da natureza transformada pelo pensamento em toda sua realidade - consciente e inconsciente, individual e coletiva - para citar as reflexões de Godelier ${ }^{11}$, encontra ambiente fértil também nas explicações etnoagronômicas cujas bases interpretativas do sistema de produção têm foco primordial na terra e no comportamento das plantas, que por sua vez é entendido por parâmetros biológicos e sociais do homem ${ }^{12}$ (HOEFFEL et al 2002).

Bem, o estudo das representações dos espaços busca apreender as experiências (temporal, espacial e social) dos grupos humanos, existindo uma relação direta e indireta entre essas representações e as ações humanas, ou seja, entre as representações e o imaginário, revolucionando a gênese do conhecimento, permitindo-nos compreender a diversidade inerente às práticas sociais. Por esse motivo não podem simplesmente ser eliminados porque constituem o cerne do processo cognitivo (KOZEL, 2002, p. 215-221).

\footnotetext{
${ }^{11}$ A fronteira entre a natureza e a cultura, a distinção entre material e o ideal tendem a se apagar quando se analisa a parte da natureza que é diretamente submetida ao homem, produzida ou reproduzida por ele (animais e plantas domésticos, ferramentas, armas, vestimentas, etc). Essa natureza exterior ao homem não é exterior à cultura, à sociedade, à história. Ela é parte da natureza transformada pela ação e assim pelo pensamento em toda sua realidade (consciente e inconsciente, individual e coletiva) do homem (GODELIER, 1984, p. 13).

${ }^{12}$ Esse é o ponto de interface, segundo Hoeffel et al (2002), entre a etnologia e a agronomia, que a partir do estudo da percepção do agricultor, da função das diferentes etapas agrícolas por ele praticadas, permite conhecer a lógica de suas ações e comportamento, assim como avaliar os mecanismos de raciocínio iguais ou diferenciados da lógica científica.
} 


\section{TERROIR: O LUGAR DA SIMBIOSE ENTRE NATUREZA E AGRICULTURAS}

De acordo a DEFFONATINES (1995, p. 166), a lição mais importante, tirada dos estudos de zonas agrícolas deprimidas e de difícil prática agrícola - as regiões montanhosas é que toda política de planejamento deve levar em conta a heterogeneidade dos agricultores assim como dos terroirs.

No que tange aos esquemas de planejamento do espaço rural, é necessário admitir que para as zonas de mais difícil agricultura deve-se evitar falar da noção convencional de vocação e potencialidade agrícolas das terras. Os zoneamentos convencionais não conseguem levar em conta as especificidades locais e a diversidade de tipos de agriculturas, isto é, a diversidade de paisagens, sabendo-se que esta última é o resultado das práticas sobre o espaço, condicionadas pelas representações locais de natureza.

Ao se constatar que a paisagem aparece cada vez mais como uma finalidade social, parece necessário, em uma perspectiva de desenvolvimento local, dispor de métodos de análise da evolução fisionômica da paisagem, e sobretudo, que inclua em suas análises " $o$ espaço percebido e representado, enquanto construção individual e coletiva, (...) em relação direta com o espaço da vida - com toda a sua intensidade e diversidade de práticas espaciais, onde intervém igualmente o imaginário, o sonho [isto é, os projetos das populações locais - grifo nosso]" (GUCHUMIAN,1989, p. 34).

Nessa perspectiva crítica, Bertrand (2005) sugere o sistema tripolar GTP (GeossistemaTerritório-Paisagem) enquanto método para entender o fenômeno Paisagem, disponibilizando para tanto ao menos três entradas principais em um mesmo território: i) o geossistema: tratando dos objetos e dos processos biofísicos que por essência já são mais ou menos antropizados; ii) o território: que leva em conta as estruturas e os funcionamentos ligados às atividades sócio-econômicas, tendo já compreendido os dados geossistêmicos e da paisagem; e iii) a paisagem: apreendendo a dimensão sensível e simbólica através das representações sócio-culturais.

Esse recorte espacial do território da produção familiar, a partir da "análise naturalista dos geossistema antropizados e da análise sócio-cultural das representações da paisagem estão fazendo evoluir os conteúdos tradicionais do ensino agronômico". Com isso, as noções de base da agronomia tais como a potencialidade, a fertilidade, os recursos naturais podem ser 
reenquadradas em um dado território, restando ao agrônomo dotar-se de um instrumental territorial eficaz; um método multidimensional para apreendê-lo ${ }^{13}$ (BERTRAND, 2005, p. 31).

Considerando-se que uma região apresenta traços particulares em parte ligados à natureza de seu ambiente e que existem normas culturais também particulares (as representações próprias a cada grupo social), cada 'território da exploração agrícola' - o terroir $^{14}$ - é assim portador de uma imagem que associa homens e meios, por conseguinte, é entendido por Cartier (2004, p.34) como: "uma representação social da percepção de diferenças naturais [e] associá-lo à população confere a esta uma origem natural local, evidentemente mítica".

A idéia é a de simbiose localizada e histórica entre os elementos naturais e a cultura própria a uma população que identifica as aptidões desses elementos naturais, ou seja, identificar as diferentes aptidões remete à evolução técnica que corresponde a uma adaptação renovada segundo as variações naturais, a evolução das normas sociais, econômicas e culturais. Essa dimensão integrativa do terroir, singularidade nascida das interações naturais, técnicas e culturais, serve em primeiro lugar ao propósito dos agrossistemas (CARTIER, 2004, p. 37).

Nesse sentido, pode-se dizer também que da mesma forma que o terroir é influenciado pelo savoir-faire local, este é dependente das condições naturais específicas das quais resultam a diversidade de adaptações humanas. A entidade terroir corresponde, assim, à simbiose de fatores naturais, de fatores tecnológicos e dos fatores sociais que geram essa tecnologia (CARTIER, 2004, p. 38).

\footnotetext{
${ }^{13}$ Para Deffontaines (1995, p. 164) "é a partir da observação da paisagem na escala do terroir e da parcela que a leitura do espaço pelos agrônomos é a mais original". O terroir tem sido definido como uma porção do espaço que possui, portanto, uma unidade fisionômica, correspondendo a um recorte do território em unidades no seio das quais a atividade agrícola parece poder ser caracterizada por uma certa homogeneidade.

${ }^{14}$ Em 1964, dois pesquisadores, Paul Pelissier e Gilles Sautter propuseram um estudo sistemático das estruturas agrárias da África intertropical e do Sahara (Atlas des terroir africains) cuja finalidade era representar toda a variedade das paisagens agrárias africanas, os documentos de base de uma tipologia das formas de ocupação do solo. Para tanto, definem o quadro operacional e a metodologia de monografias de terroir: "um território contínuo inteiramente submetido, segundo uma intensidade e modalidades variadas, à exploração agrícola". Por terroir os pesquisadores também comprendem "a porção de território apropriado, gerenciado e utilizado pelo grupo que aí reside e dai tira seus meios de existência". O termo só faz sentido na medida em que o solo é o objeto de uma exploração de caráter agrícola, cuja marca na paisagem pode ajudar grandemente a reconhecer os limites de um terroir individualizando-o em relação à natureza "desocupada" ou em relação às células rurais vizinhas (SAUTTER e PÉLISSIER, 1964, p. 57 e 58).
} 


\section{O ESTUDO GEO-SÓCIO-AGRONÔMICO DA PAISAGEM RURAL DE RIO BRANCO DO SUL-PR: ALGUNS RESULTADOS}

Desvendar as múltiplas dimensões da paisagem torna-se um objetivo audacioso que só pode ser concebido a partir de um projeto de estudo interdisciplinar. A investigação das dimensões sociais da paisagem rural (das representações e percepções de natureza) e das suas dimensões físicas (a estrutura e o funcionamento dos geossistemas), a partir do referencial teórico-metodológico do terroir, prevê em seu método a interpretação e a comparação de dois discursos: a do pesquisador (do cientista que possui um entendimento acerca das relações dos elementos da paisagem) e dos agricultores ecológicos de Rio Branco do Sul que possuem um entendimento operacional e estético, geralmente distinto, a cerca das dinâmicas produtivas da natureza.

Nesse sentido, a sugestão da abordagem multidimensional da paisagem exige em sua matriz um pensamento complexo que permita captar as diversas formas da relação dinâmica entre sociedade e natureza. Uma leitura da complexidade inerente aos sistemas ambientais foi pensada por Georges Bertrand (2005) - o GTP (Geossistema, Território e Percepção). Com isso, ele nos fornece subsídios ao estudo dos Terroirs.

$\mathrm{Na}$ base da compartimentação da paisagem em unidades espaciais homogêneas (ou unidades elementares de paisagem) está presente o conceito de Geossistema, visto por Bertrand (1971) como uma categoria espacial de relativa cuja homogeneidade dos seus componentes se dá no nível das relações e dos processos e é concretizada quando da delimitação simplória da paisagem no nível da aparência, isto é, fisionomicamente ${ }^{15}$.

Análise dos atributos geossistêmicos das Bacias Hidrográficas do Rio São Pedro e Rio Morro Grande, nas quais localizam-se as quatro comunidades (Campina dos Pintos, Pinhal Grande, Capiru Boa Vista e Capiru dos Epifânio) onde vivem os agricultores ecológicos de Rio Branco do Sul (RBS).

Para concretizar a compartimentação do geossistema em unidades fisionômica homogêneas partiu-se da necessidade de inventariar e produzir dados relativos aos elementos

\footnotetext{
${ }^{15}$ Embora o geossistema possa não apresentar necessariamente uma grande homogeneidade fisionômica, sua delimitação em unidades de paisagem pode ocorrer em se destacando as descontinuidades objetivas da paisagem (BERTRAND, 1971), ou ainda, respeitando-se os princípios de analogia, homogeneidade relativa, repetibilidade e pertinência de padrões (regularidades) dos objetos agenciados no espaço (RODRIGUEZ et al, 2007) .
} 
do meio físico e biológico a fim de caraterizar a Paisagem no Contexto Regional. Esse procedimento previu os seguintes levantamentos bibliográficos e cartográficos:

a) Mapa geológico das Folhas A098 A100 e A103 da Região Metropolitana de Curitiba (escala 1:20.000) do 'Projeto Geotecnia-RMC', a MINEROPAR (1997);

b) Carta Planialtimétrica: Folhas SG-22-X-D-I-1 e SG-22-X-C-III-2 da COMEC (1976) na escala Escala 1:50.000;

c) Mapa de Levantamento de Reconhecimento dos Solos do Estado do Paraná, na escala 1:600.000 (EMBRAPA, 1981);

d) Dados referentes ao uso e ocupação do solo das propriedades inventariadas correspondem às imagens de sensoriamento remoto disponibilizadas na Internet pelo software Google Earth (2006); acessadas em 08/10/2006. Ao emprego de imagens associou-se o método da toposseqüência que exigiu do entrevistador e dos entrevistados o deslocamento até o ponto mais alto da propriedade a fim de obter uma visualização geral da paisagem.

e) Produção cartas de Declividade, Hipsometria, Perfil Longitudinal e Transversal dos Rios, Imagens sombreadas 3D a partir da geração de modelos numéricos do terreno derivados das curvas planialtimétricas digitalizadas em ambiente de geoprocessamento SPRING 4.3.3 (CÂMARA et al, 1996).

f) Elaboração do mapa-síntese com proposta de Unidades de Paisagem.

A compartimentação do geossistema delimitado pelo recorte hidrográfico resultou em ete Unidades de Paisagem, das quais três configuram a base biofísica dos Terroirs da agricultura de base ecológica de RBS. A FIGURA 1 representa o mapa das Unidades elementares de Paisagem onde é possível localizar os respectivos "terroirs da agricultura de base ecológica" identificados na área estudada. 
FIGURA 1. UNIDADES ELEMENTARES DE PAISAGEM DA ÁREA ESTUDADA E OS SEUS RESPECTIVOS TERROIRS

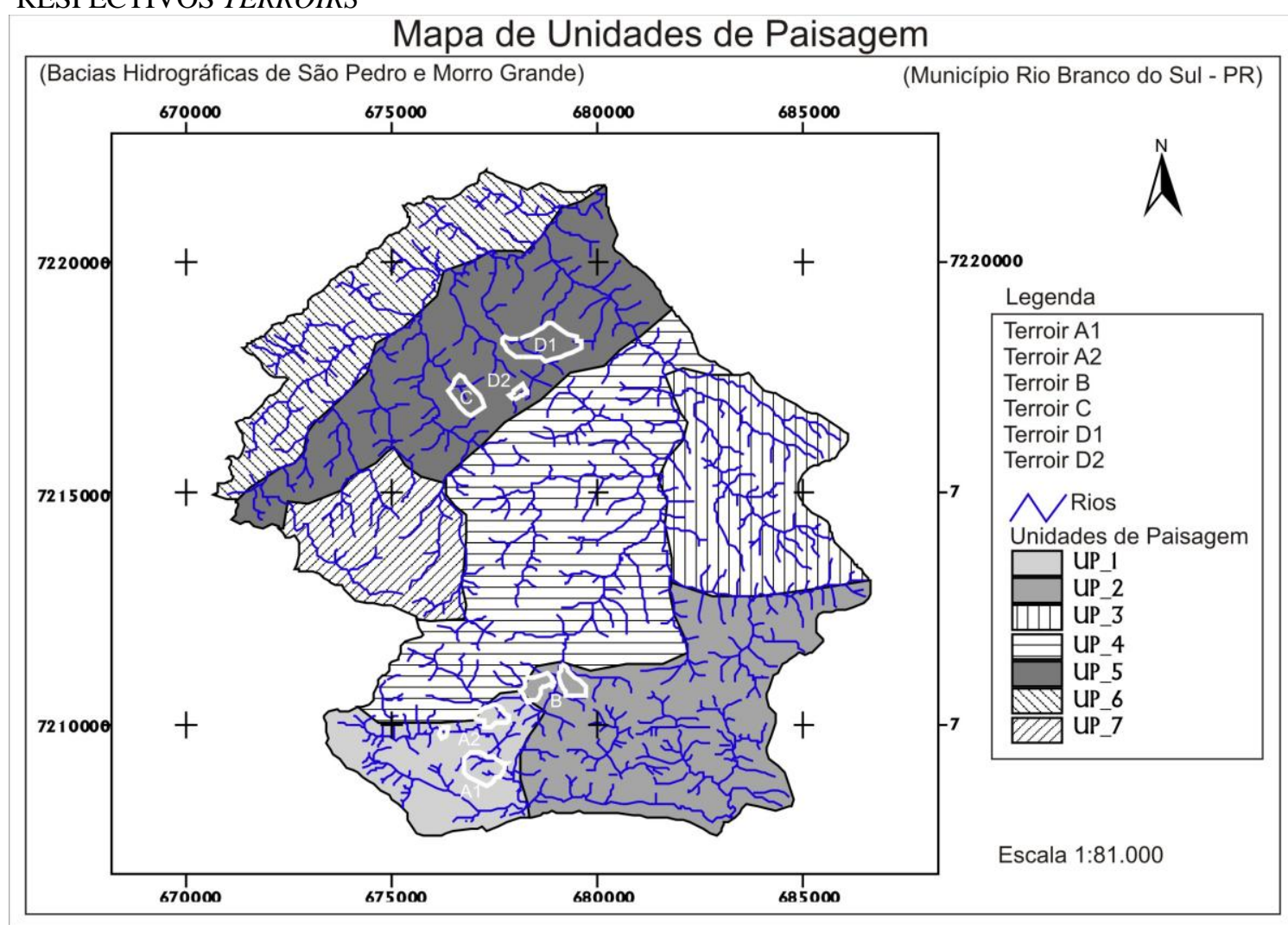

Assim, o processo de compartimentação do geossistema em Unidades de Paisagem requereu a sobreposição de mapas temáticos previamente produzidos no intuito de uma análise conjunta dos seus atributos físicos e uma percepção orientada da paisagem e de todos os dados mapeados. A conjugação de uma série de mapas sobre o ambiente natural (geomorfológico, hidrológico, climatológico, etc) permite a previsão - a prognose geográfica - do comportamento ${ }^{16}$ do seu conjunto (SOTCHAVA, 1977).

Conforme a Tabela 1 é possível verificar os dados quantitativos provenientes da síntese entre as cartas temáticas de Geologia, Hipsometria e Declividade das respectivas Unidades de Paisagens identificadas. Nas unidades fisionômicas homogêneas, agrupadas segundo os geofácies - ordem taxonômica elementar do geossistema caracterizada pelo desenvolvimento de uma mesma fase de evolução geomorfofógica (BERTRAND, 1968, p. 17), inserem-se os terroirs.

\footnotetext{
${ }^{16} \mathrm{O}$ comportamento dos geossistemas frente às perturbações (naturias ou antrópicas) é interpretado a partir da análise da evolução geral dos geossistemas e suas subunidades, a partir da qual busca-se identificar estágios de estabilidade dinâmica - steady state, conforme CHORLEY (1971) - que apontem para mudanças gerais em termos de fluxos de energia, matéria e fisionomia, usando tradicionalmente alguns critérios da bio-resistasia de H. Erhart, da morfopedogenênese de J.Tricart, entre outros.
} 
TABELA 1. SÍNTESE DE TRÊS UNIDADES DE PAISAGEM IDENTIFICADAS

\begin{tabular}{|c|c|c|c|c|c|c|c|c|c|c|c|}
\hline \multicolumn{3}{|c|}{ UP } & \multicolumn{3}{|c|}{ Geologia } & \multicolumn{3}{|c|}{ Hipsometria } & \multicolumn{3}{|c|}{ Declividade } \\
\hline \multirow{7}{*}{1} & ha & $\%$ & Classe & ha & $\%$ & Classe & ha & $\%$ & Classe & ha & $\%$ \\
\hline & & & & & & & & & $P$ & 254,64 & 27,9 \\
\hline & & & Metadolomitos & 804,68 & 95,54 & 920 a 1020 & 647 & 70,94 & S.O & 89,16 & 9,77 \\
\hline & 912 & 7,07 & Metapelitos & 40,68 & 04,46 & 1020 a 1120 & 266 & 29,16 & M.O. & 101,08 & 11,0 \\
\hline & & & & & & & & & $\mathrm{O}$ & 187,16 & 20,5 \\
\hline & & & & & & & & & F.O & 255,36 & 28 \\
\hline & & & & & & & & & M & 24,04 & 2,63 \\
\hline \multirow{6}{*}{2} & \multirow{6}{*}{2281} & \multirow{6}{*}{17,68} & & & & & & & $\mathrm{P}$ & 327,44 & 14,2 \\
\hline & & & & & & & & & S.O & 145,64 & 6,35 \\
\hline & & & Metadolomitos & 1503,40 & 65,81 & 920 a 1020 & $167, .92$ & 73,38 & M.O & 211,64 & 9,23 \\
\hline & & & Metamargas & 481,44 & 21,08 & $1020-1120$ & 313,20 & 13,56 & $\mathrm{O}$ & 437,52 & 19,0 \\
\hline & & & Metapelitos & 299,28 & 13,11 & 820 a 920 & 309,00 & 13,06 & F.O & 937,76 & 40,8 \\
\hline & & & Metadolomitos & 1503,40 & 65,81 & 920 a 1020 & $\begin{array}{l}1673,9 \\
2\end{array}$ & 73,38 & M & 215,6 & 9,41 \\
\hline \multirow{6}{*}{5} & \multirow{6}{*}{2484} & \multirow{6}{*}{19,25} & & & & & & & $\mathrm{P}$ & 182,52 & 7,35 \\
\hline & & & Metassiltitos & 255,52 & 10,29 & 620 a 720 & 313,28 & 12,61 & SO & 51,24 & 2,06 \\
\hline & & & Metodolomitos & 1154,52 & 46,48 & 720 a 820 & 805,00 & 32,41 & MO & 127,16 & 5,12 \\
\hline & & & Metapelitos & 837,08 & 33,69 & 820 a 920 & $\begin{array}{l}1008,0 \\
0\end{array}$ & 40,58 & $\mathrm{O}$ & 350,56 & $\begin{array}{r}14,1 \\
1\end{array}$ \\
\hline & & & Metamargas & 99,56 & 4,01 & 920 a 1020 & 331,04 & 13,32 & FO & 1268,88 & 51,0 \\
\hline & & & Metabasitos & 137,56 & 5,53 & 1020 a 1120 & 27,16 & 1,09 & M & 469,32 & 18,8 \\
\hline
\end{tabular}

Legenda: UP (Unidades de Paisagem); P (Plano), S.O. (Suave Ondulado), M.O. (Moderadamente Ondulado), O (Ondulado), F.O. (Forte Ondulado), M (Montanhoso).

Fonte: Floriani (2007).

Para a escala dos terroirs propusemos uma classificação que possibilitasse identificar as transformações fisionômicas de suas glebas e talhões ${ }^{17}$. Para tanto, buscamos expressar essas mudanças em termos de sucessão e rotação de cultivos, criando uma escala de caracterização dos estágios evolutivos da paisagem agrícola que comportasse a maior e menor diversidade

\footnotetext{
${ }^{17}$ Para Deffontaines (1995, p.27-28), nessa escala são percebidos "os componentes variados da paisagem: as condiçães do meio físico, as coberturas vegetais, os dispositivos que são os traços mais ou menos perenes sobre o território, as práticas agrícolas permitindo a resolução de problemas de acesso, de limites, de declives, etc (..) Enfim, a terceira escala é aquela da parcela. [Observa-se] ai os mesmos componentes precedentes, mas com mais detalhes devido ao poder separador da escala (...). Esta escala de análise é fundamental, pois as práticas agrícolas representam a chave visual do conhecimento dos sistemas de cultura e criação" (DEFFONTAINES, 1995, p. 27-28).
} 
em termos de mudanças espaço-temporais da cobertura vegetal cultivada, isto é o manejo da biomassa (FIGURA 2).

A identificação dos terroirs deve tomar por base, segundo Sauter e Pélissier (1964), a caracterização dos atributos biofísicos da paisagem valorizados pelos agricultores, pois nestes atributos estão compreendidas suas práticas de paisagem. Dessa equação (prática+natureza) resulta a conformação dos Terroirs que são caracterizados pela valorização de suas singularidades, a partir das quais são criados os graus de riqueza dos mesmos, resultantes do acúmulo das características naturais e do conhecimento local.

FIGURA 2. GRUPO DE PRÁTICAS (GP) CONFORME DIVERSIDADE ESPAÇO-TEMPORAL DA BIOMASSA MANEJADA NOS “TERROIRS ECOLÓGICOS” DE RBS.

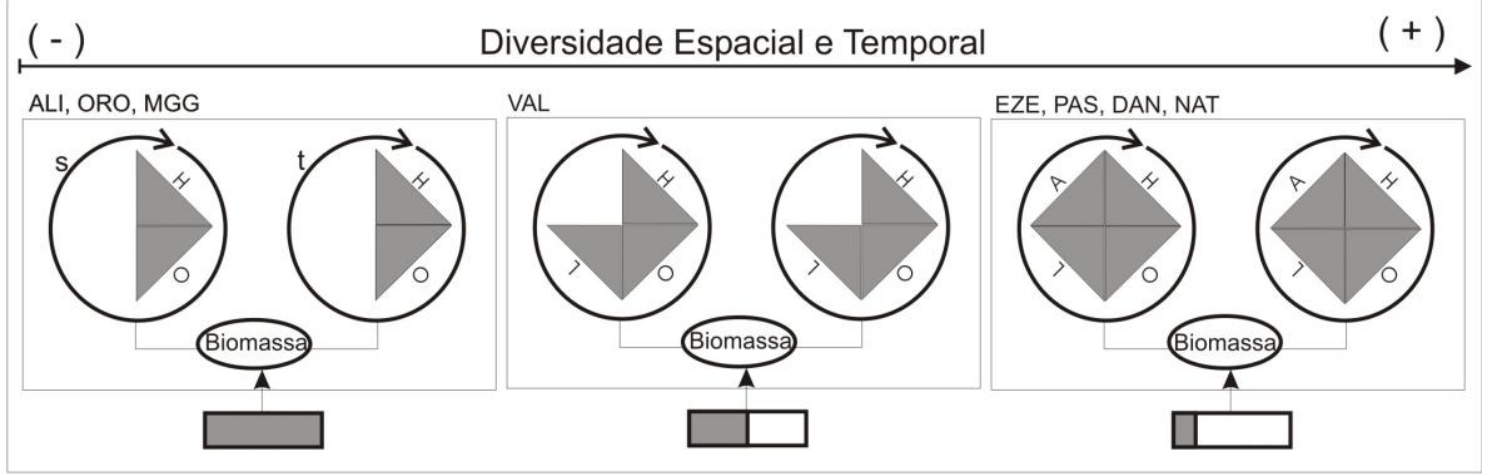

Legenda: —Composto Orgânico (insumo externo); H: Herbáceas;O: Olericolas; L: Lavoura s: rotação; t: sucessão Legenda: H (herbáceas); O (olerícolas); L (Lavoura); A (arbóreas e arbustivas); ALI, ORO, MGG, VAL, EZE, PAS, DAN, NAT (iniciais dos nomes dos agricultores proprietários estabelecimentos agroecológicos).

Fonte: Floriani (2007).

O sistema de produção de base ecológica empreendido nas propriedades principais, sejam eles mais ou menos centralizados na olericultura ou na produção de alimentos para subsistência (grãos, milho, mandioca) e lenha (bracatinga), têm como finalidade, desde o ponto de vista edafológico, a manutenção da fertilidade do solo e da sanidade geral da planta, através do incremento da matéria orgânica no solo. isto é, a partir do manejo da biomassa. Assim, três grupos de práticas de manejo da comunidade biótica são configuradas pelos AEs de RBS. Tais grupos, de acordo a Floriani (2007), configuram paisagens com diferentes níveis de diversidade espacial e temporal: 
1. O primeiro grupo de práticas (GP1) - conforme a FIGURA 3 - é caracterizado pela redução da diversidade espacial e temporal dos cultivos sucessionais e rotacionais. A intensificação da produção centrada na olericultura orgânica faz com que a paisagem das propriedades alterne sua fisionomia entre dois tipos de plantas: as olerícolas e as plantas espontâneas pioneiras (colonizadoras) ou aquelas cultivadas para fins de adubação verde (exóticas ou nativas, por exemplo, aveia-preta no inverno e papuã no verão). Contudo, geralmente o entorno da propriedade é preservado, caracterizando uma ilha de produção cercada por áreas de vegetação nativa de porte arbóreo (a mata secundária mais ou menos restaurada em sua condição climáxica original). Neste grupo encaixam-se os agricultores ALI, ORO e MGG.

2. O segundo grupo de práticas (GP2) é caracterizado pelo aumento da diversidade espacial e temporal. $\mathrm{O}$ manejo das populações vegetais abrange a alternância das lavouras com as olerícolas e as herbáceas (espontâneas e/ou manejadas com finalidade de cobertura). Contudo, neste grupo de sistema de práticas, o manejo das plantas arbóreas no entorno da propriedade não é realizado, restringindo-se às áreas contíguas às residências. Neste grupo encontra-se apenas o estabelecimento de VAL.

3. O terceiro grupo de praticas (GP3) é caracterizado pelo manejo de todos os estágios sucessionais de vegetação, isto é, a diversidade têmporo-espacial é maximizada na paisagem. O manejo das populações vegetais alternam-se e/ou dividem a mesma área no mesmo período de tempo (consórcio) entre as herbáceas (espontâneas e de adubos-verde), as olerícolas, as de lavoura (grãos e mandioca) e as arbóreas (bracatingas, entre outras). Este grupo subdivide-se em dois: o subgrupo mais sucessional e o subgrupo mais rotacional, isto é, existem propriedades onde o esquema de manejo dos quatro tipos de populações de plantas expressam-se mais no estágio rotacional que sucessional: nestas propriedades (NAT, EZE, PAS) ocorrem sucessões entre as olerícolas, herbáceas e lavouras, mas também a rotação com a Bracatinga; ao passo que nas propriedades mais sucessionais ocorrem a implementação da agrofloresta (DAN), ou seja, na sucessão ocorrem também as espécies arbóreas (bracatinga, tupichava) (FLORIANI, 2007, p. 169).

Essas similaridades em torno às práticas de manejo da comunidade biótica configuramse em um dos elementos-chave de análise da paisagem, dando identidade ao Terroir. A identificação dos terroirs buscará basear-se na caracterização dos atributos biofísicos da paisagem valorizados pelos agricultores, pois nestes atributos estão compreendidas suas práticas de paisagem. Dessa equação (prática+natureza) resulta a conformação dos Terroirs, que segundo Sauter e Pélissier (1964) são caracterizados "pela valorização de suas singularidades, a partir das quais são criados os graus de riqueza dos mesmos, resultantes do acúmulo das características naturais e do conhecimento local”.

Tomando-se como recomendação a reflexão de Blanc-Pamard (1986) a respeito da decifração do código ecológico global do(a) agricultor(a), o caminho investigativo deveria passar pela observação da maneira como o agricultor vê seu meio e a ele adapta suas atividades, isto é, referenciar o ambiente percebido (o meio visto e utilizado), relacionando a mecânica da utilização do meio com a percepção-classificação do agricultor, ou da 
comunidade em que está inserido.

Portanto, nessa etapa, uma grande importância foi dada aos termos locais que os agricultores empregam para nomear, identificar e classificar o meio. Duas ações para explicitar e decodificar o ambiente percebido são utilizadas pelo agricultor: a descrição enquanto um ato de construção, a partir da palavra, do nível da percepção, e a classificação (ou designação) das paisagens e das suas terras (BLANC-PAMARD, 1986).

A identificação e caracterização das percepções e representações vernaculares a respeito das qualidades edáficas, dos outros elementos constituintes das paisagens (litologia, microclima, geomorfologia, vegetação) e de seus comportamentos frente aos processos produtivos foi realizada a partir da apresentação do referencial iconográfico (fotos aéreas, conforme FIGURA 4) da paisagem local aos agricultores entrevistados, seguido da técnica da toposseqüência e transecto.

Tais técnicas pertencem também ao corpo de ferramentas do Diagnóstico Rural Participativo $^{18}$ que mobiliza diversas abordagens (ou processos) e técnicas utilizadas no planejamento, implementação, monitoramento e avaliação de gestão de recursos naturais (SEIXAS, 2005).

Conforme DEBARBIEUX e LARDON (2003, p. 7), a representação iconográfica dos fenômenos da paisagem constitui uma modalidade privilegiada de compreensão das estruturas e dinâmicas espaciais. Nesse sentido ela constitui um instrumento heurístico largamente utilizado pelos pesquisadores, agrônomos e geógrafos. Ela constitui igualmente um instrumento precioso para o exercício do diagnóstico territorial e para uma metodologia reflexiva com os atores na medida que guiam individualmente e coletivamente um raciocínio espacial. Nesse sentido, constitui uma ferramenta de visualização e coloca em discussão os pontos de vista dos atores e de suas práticas de paisagem contribuindo na transformação dos territórios.

\footnotetext{
${ }^{18}$ O Diagnóstico Rural Participativo (DRP) é um conjunto de técnicas e ferramentas que permite que as comunidades façam o seu próprio diagnóstico e a partir daí comecem a autogerenciar o seu planejamento e desenvolvimento. Tal instrumental metodológico se insere no âmbito da pesquisa participativa, difundida principalmente nos anos 90, tornando-se uma ferramenta muito útil para o envolvimento comunitário no desenvolvimento e na gestão de Recursos Naturais. Desta maneira, os participantes poderão compartilhar experiências e analisar os seus conhecimentos, a fim de melhorar as suas habilidades de planejamento e ação (COELHO, 2007; SEIXAS, 2005)
} 


\section{FIGURA 4. MAPEAMENTO E CLASSIFICAÇÃO VERNACULARES DAS TERRAS}

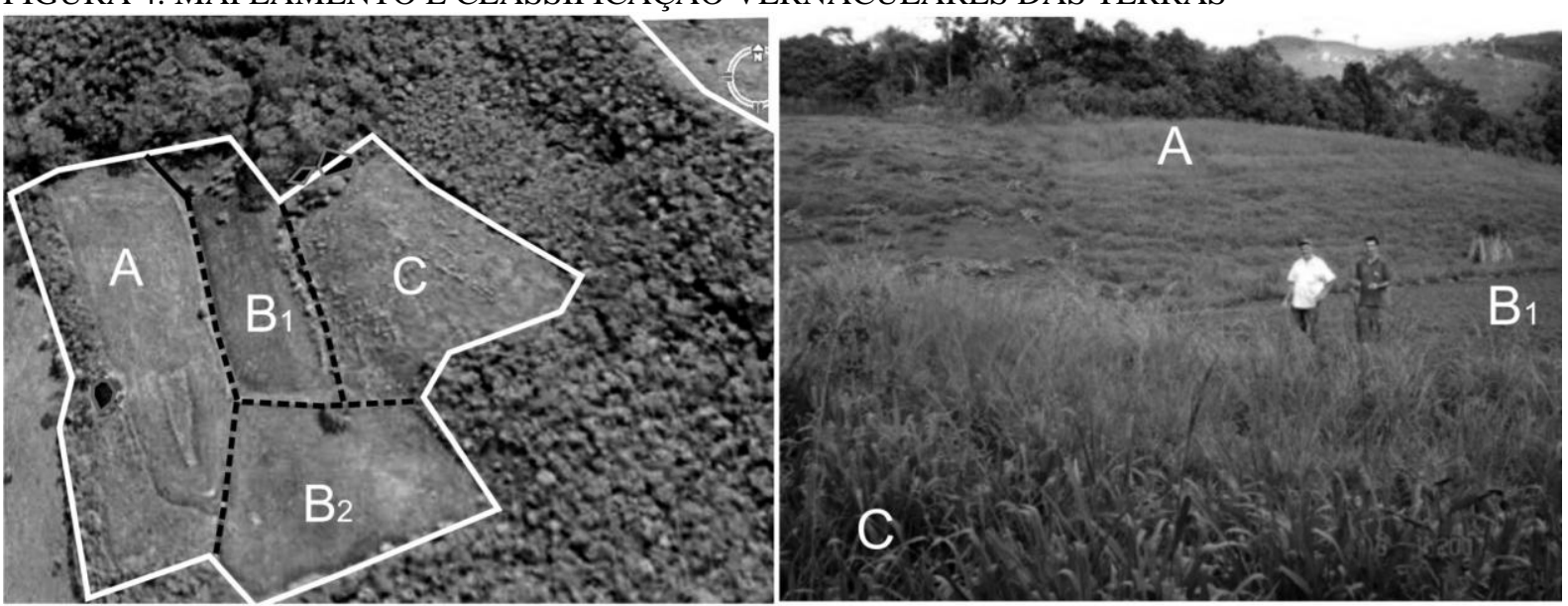

Legenda:

A - "Terra-vermelha-dura":da lomba, vermelha, mais barrenta, dura, de difícil trabalho

B - "Terra-vermelha": de canhada, vermelha, barrenta, seca mais rápido

C - "Terra-areia": de lomba, arenosa, seca devagar, muito sombreada

Fonte:GOOGLE EARTH (2006)

Elaborado: Floriani (2007)

Técnicas interativas de produção de imagens do território são relatadas por autores que trabalham a questão da gestão coletiva da paisagem, no intuito de produzir Mapas Cognitivos a partir de recursos iconográficos como fotografias da paisagem e croquis coletivos ou individuais dos estabelecimentos envolvidos (MICHELYN, 1998; LELLI, 2003; LETISSIER, 2003).

O exame da matriz cognitiva (o sistema de diagnose e classificação) vernacular da paisagem e dos solos nela contidos visou o entendimento das categorias e parâmetros de valoração construídos pelos agricultores, isto é, o entendimento do sistema vernacular de avaliação passou pela interpretação de informações referentes ao universo conceitual e prático ligado aos pressupostos que fundamentam o sistema cognitivo.

Do apontamento dos atributos e parâmetros avaliativos construídos pelos agricultores, elaborou-se uma matriz cognitiva representativa para o grupo, hierarquizando os parâmetros em função da importância no processo avaliativo das terras e das paisagens. No quadro 3 é possível verificar alguns dos atributos e parâmetros avaliativos extraídos do contexto de uma das entrevistas realizadas. 
QUADRO 3. ATRIBUTOS AVALIATIVOS DA CLASSIFICAÇÃO VERNACULAR DAS TERRAS

\begin{tabular}{|c|c|c|c|c|c|c|c|c|c|}
\hline \multirow{2}{*}{\multicolumn{2}{|c|}{ Nomenclatura }} & \multicolumn{8}{|c|}{ Atributos } \\
\hline & & \multirow{2}{*}{$\begin{array}{c}\text { Posição no } \\
\text { Terreno }\end{array}$} & \multirow{2}{*}{$\begin{array}{c}\text { Cor } \\
\text { Escura }\end{array}$} & \multirow{2}{*}{$\begin{array}{c}\text { Matéria } \\
\text { Orgânica } \\
\text { Gorda }\end{array}$} & \multirow{2}{*}{$\begin{array}{l}\text { Manuseio } \\
\text { Pega mais }\end{array}$} & \multirow{2}{*}{$\begin{array}{c}\text { Textura } \\
\text { Barrenta }\end{array}$} & \multirow{2}{*}{$\begin{array}{l}\text { Estrutura } \\
\text { Massuda }\end{array}$} & \multirow{2}{*}{$\begin{array}{l}\text { Acidez } \\
\text { Menos }\end{array}$} & \multirow{2}{*}{$\begin{array}{c}\text { Pedregosidade } \\
\text { Ausente }\end{array}$} \\
\hline 1 & $\begin{array}{l}\text { Terra- } \\
\text { Gorda } \\
\end{array}$ & & & & & & & & \\
\hline 4 & $\begin{array}{l}\text { Terra- } \\
\text { Magra }\end{array}$ & Lomba & clara & Magra & $\begin{array}{l}\text { Pega } \\
\text { menos }\end{array}$ & $\begin{array}{l}\text { Arenosa } \\
\text { (solta) }\end{array}$ & Seca & Mais & Presente \\
\hline
\end{tabular}

Fonte: Floriani (2007)

As similaridades e diferenças das práticas de manejo da comunidade biótica configuram-se em um dos elementos-chave de análise da paisagem. Da identificação das práticas foi possível caracterizar três grupos de manejo da comunidade biótica (verificar Figura 2) agenciadas pelos agricultores ecológicos de RBS. Tais grupos configuram paisagens com diferentes níveis de diversidade espacial e temporal. No QUADRO 4 é possível verificar a síntese dos elementos que compõem os "terroirs ecológicos" existentes em RBS.

QUADRO 4. SÍNTESE DOS ELEMENTOS CONSTITUINTES DOS “TERROIRS ECOLÓGICOS"

\begin{tabular}{|c|c|c|c|c|c|c|c|c|}
\hline \multirow[t]{2}{*}{ U.P. } & \multicolumn{2}{|c|}{ Relevo } & \multirow[t]{2}{*}{ Solos } & \multirow{2}{*}{$\begin{array}{c}\text { Grupo de } \\
\text { Práticas }\end{array}$} & \multirow[t]{2}{*}{ Estabelec. } & \multirow[t]{2}{*}{ Comunidade } & \multirow{2}{*}{$\begin{array}{l}\text { SubBacia } \\
\text { Hidrográfica }\end{array}$} & \multirow[t]{2}{*}{ Terroir } \\
\hline & Posição & Declividade & & & & & & \\
\hline \multirow{3}{*}{1} & Interflúvio & S.O. a M.O. & $\begin{array}{c}\text { Cambissoloe } \\
\text { Argissolos }\end{array}$ & \multirow{3}{*}{1} & \multirow{3}{*}{$\begin{array}{l}\text { ALI } \\
\text { ORO } \\
\text { MGG }\end{array}$} & \multirow{3}{*}{$\begin{array}{c}\text { Campina dos } \\
\text { Pintos }\end{array}$} & \multirow{3}{*}{$\begin{array}{c}\text { Rio } \\
\text { Pessegueirinho }\end{array}$} & \\
\hline & Vale & P a S.O. & Latossolos & & & & & Al \\
\hline & Interflúvio & O a F.O. & $\begin{array}{l}\text { Latossolos, } \\
\text { Cambissolo e } \\
\text { Argissolos }\end{array}$ & & & & & A2 \\
\hline \multirow[b]{2}{*}{2} & Vale & O a F.O. & $\begin{array}{l}\text { Cambissolo } \\
\text { Húmicos }\end{array}$ & \multirow[t]{2}{*}{2} & \multirow[t]{2}{*}{ VAL } & \multirow{2}{*}{$\begin{array}{l}\text { Pinhal } \\
\text { Grande }\end{array}$} & \multirow{2}{*}{$\begin{array}{l}\text { Rio Grande da } \\
\text { Laura }\end{array}$} & \multirow[b]{2}{*}{ B } \\
\hline & Interflúvio & $\mathrm{O}$ a F.O. & $\begin{array}{l}\text { Argissolos e } \\
\text { Cambissolos }\end{array}$ & & & & & \\
\hline \multirow{4}{*}{5} & Vale & P a S.O. & Argissolos & \multirow{4}{*}{3} & \multirow{2}{*}{ DAN EZE } & \multirow{4}{*}{$\begin{array}{c}\text { Capiru Boa } \\
\text { Vista }\end{array}$} & \multirow{4}{*}{ Rio da Lança } & $\mathrm{C}$ \\
\hline & \multirow{3}{*}{ Interflúvio } & \multirow{3}{*}{ F.O. a M } & \multirow{3}{*}{$\begin{array}{l}\text { Argissolos e } \\
\text { Cambissolo }\end{array}$} & & & & & D1 \\
\hline & & & & & DAN, EZE & & & \multirow[b]{2}{*}{ D2 } \\
\hline & & & & & PAS & & & \\
\hline
\end{tabular}

Legenda: Legenda: P (Plano), S.O. (Suave Ondulado), M.O. (Moderadamente Ondulado), O (Ondulado), F.O. (Forte Ondulado), M (Montanhoso); ALI, ORO, MGG, VAL, EZE, PAS, DAN, NAT (iniciais dos nomes dos agricultores proprietários estabelecimentos agroecológicos).

Fonte:(2007).

A partir da matriz-síntese explicitada no quadro acima, descreveremos parcialmente o Terroir D, com suas subdivisões, de forma a propiciar ao leitor um relativo entendimento da caracterização da complexidade espacial que identificam os territórios agroecológicos de RBS. Assim, temos conforme Floriani (2007) que: 
(...) contrariamente aos outros terroirs - onde a "canhada" (termo vernacular utilizado para designar as caneluras das vertentes onde pode se estabelecer uma drenagem intermitente) apresenta-se propícia ao cultivo de olerícolas, devido à baixa declividade e aos solos profundos derivados muitas vezes de sedimentos alóctones o Terroir D caracteriza-se pela agricultura praticada no terço inferior das encostas ou em seus topos. Neste terroir pratica-se alta diversidade espacial e temporal do manejo da biomassa, sendo cultivado com todos os estágios sucessionais de vegetacão da paisagem (olerícolas, herbáceas, lavouras e arbóreas). Contudo, mesmo o manejo da biomassa sendo considerado de alta diversidade, no território de DAN essa sucessão de espécies é maximizada, isto é, ocorre a implementação da agrofloresta com espécies arbóreas nativas, o que faz com que o terroir D seja dividido em duas subunidades: D1, caracterizado pelas práticas mais rotacionais de manejo dos cultivos, e D2 pelo manejo mais sucessional que rotacional da biomassa. Outra característica em comum é a independência ou dependência mínima do composto orgânico, explicada pela descentralização das espécies olerícolas no sistema produtivo, gerando uma baixa intensidade dos processos produtivos que exigem constante reposição dos níveis de matéria orgânica. O preparo dos solos no Terroir $D$ restringe-se ao preparo das covas, ou ao revolvimento mínimo do solo. A roçada sem queimada faze parte das práticas de manejo da biomassa da população arbórea (o bracatingal) e herbácea do Terroir D1, ao passo que a roçada tradicional (com queimada) caracteriza o Terroir D2. Por fim, no Terroir D, com um todo, as áreas de mata nativa conservadas nas posições mais íngremes das encostas garantem uma alta diversidade paisagísitica (fisionômica) a esse território de cultivo (FLORIANI, 2007, p. 197).

(...) [Algumas] características próprias aos três terroirs (A, B e C) configuram um cenário onde estão presentes práticas da agricultura convencional, expressas principalmente pela motomecanização das terras, através do emprego do microtrator. Tal tecnologia, parece conferir um certo status de independência a esses agricultores (herança, talvez, do mito da modernização agrícola) que, como dito anteriormente, é percebido como imprescindível à atividade agrícola. De modo contrário, no Terroir $\mathrm{D}$, o preparo do solo é limitado à técnicas rudimentares pelo fato desses agricultores empreenderem o sistema de plantio direto (DAN), ou por implantarem coletivamente o terraceamento [vide a horta comunitária], buscando com isso a conservação das terras contra a erosão, ou ficarem de acordo aos princípio da agroecologia. Outra prática herdada e que vigora principalmente no Terroir A e B é a adubação orgânica por meio da compostagem. Atualmente nos Terroirs A, B e C implementa-se uma olericultura orgânica cuja produção interna do composto é insuficiente para sustentar tal atividade. Algumas justificativas poderiam explicar esse balanço negativo de produção de composto orgânico: a atividade pecuária não pertenceria à tradição agrícola desses agricultores ou porque também lhes faltariam mais áreas disponíveis para tal implementarem tal atividade (FLORIANI, 2007, p.286)

O recorte histórico da ocupação e da formação social da Região Metropolitana de Curitiba foi fundamental para evidenciar os principais aspectos relacionados às transformações do sistema natural e as mudanças demográficas, sociais, econômicas e técnicas ocorridas na escala da região e da microrregião do Vale do Ribeira:

As quatro comunidades rurais onde se inserem os estabelecimentos da produção agrícola de base ecológica contam com dezenove (19) pessoas envolvidas, direta e indiretamente, na produção agrícola ecológica no município de RBS, das quais dezessete (17) têm participação direta na agricultura. Essa amostra distribui-se nas 
quatro comunidades vizinhas: sete agricultores na Campina dos Pintos, quatro no Pinhal Grande, dois no Capiru Boa Vista e quatro no Capiru dos Epifânio. As referidas comunidades foram agrupadas em função de suas particularidades histórico-culturais: devido ao processo histórico de colonização da área, os descendentes de imigrantes italianos ocupam atualmente três das quatro localidades, habitando a porção sul e central da área estudada: os Fioresi, os Gasparin e os Cavassin. Ao passo que a localidade situada na porção setentrional da bacia hidrográfica é ocupada pela população tradicional da região do Vale do Ribeira, resultante da miscigenação das etnias portuguesa e indígena (FLORIANI, 2007, P.141).

De modo geral, as razões pelas quais os agricultores das quatro localidades resolveram dedicar-se à produção de base ecológica são : saúde (pessoal e familiar para $100 \%$ dos entrevistados), ambientais (conservação dos recursos para 70,58\%) e econômicas $(52,94 \%)$. Há unanimidade nas respostas quando indagados sobre o fato da agricultura de base ecológica melhorar as condições de vida (todos afirmam, com exceção de 1 resposta "não sabe"), da mesma forma que quando indagados sobre o fato da agricultura ecológica conseguir preços melhores no mercado (FLORIANI, 2007, p. 142).

Na seqüência, seguiu-se ao exame diagnóstico da paisagem física que foi desdobrado em duas fases: na primeira fase, buscou-se caracterizar os pressupostos implícitos no sistema cognitivo vernacular (Figura 3); na segunda, buscou-se compará-los com aqueles identificados no Sistema de Avaliação da Aptidão Agrícola das Terras (SAAT, Ramalho Filho e Beek, 1994) e Sistema de Capacidade de Uso das Terras (SCUT, Lepsch et al, 1983) de forma a analisar as congruências ou incongruências avaliativas (Tabela 4).

TABELA 4. COMPARAÇÃO DOS PARÂMETROS AVALIATIVOS CIENTÍFICOS E VERNACULAR

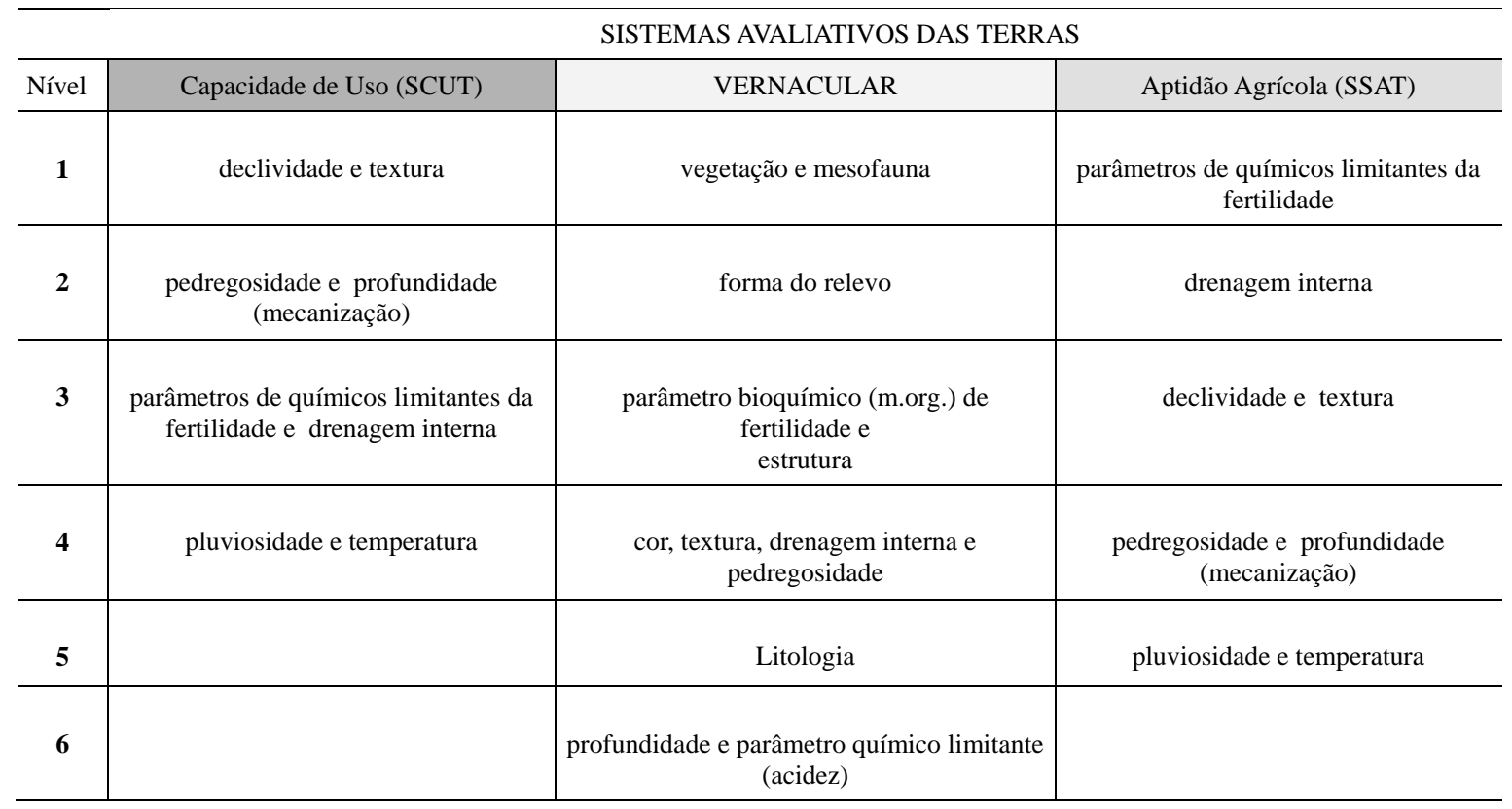

Fonte: Floriani (2007). 
Por fim, o evidenciamento de certos parâmetros constituintes de um mapa cognitivo coletivo (QUADRO 5) - a partir da análise dos discursos sobre a qualidade das terras, sobre as práticas agrícolas e o mapeamento e classificação das paisagens por parte dos agricultores buscou destacar sinteticamente as racionalidades implícitas nos esquemas científico e vernacular, desvendando os ideais e fundamentos próprios de cada saber, que irá imprimir um modo de relacionamento com a natureza.

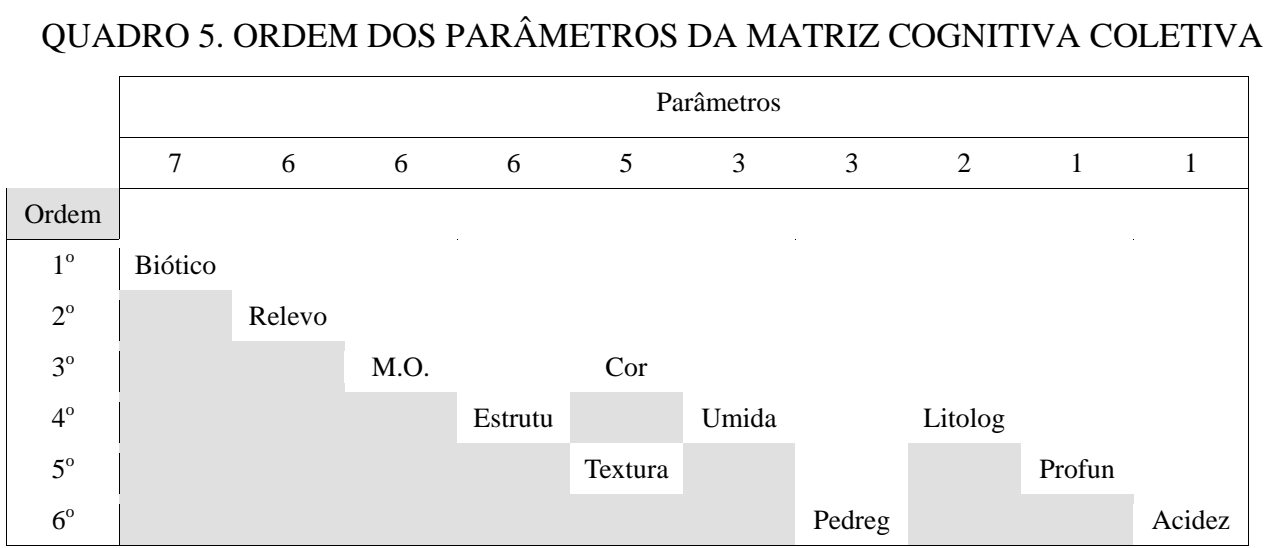

Fonte: Floriani (2007).

De acordo ao QUADRO 5, temos que o parâmetro Biótico aparece em primeiro lugar em termos de citações (entrevista), além de ser o primeiro parâmetro a ser destacado na avaliação vernacular das terras. Seguem os demais parâmetros que ocupam distintos lugares de acordo ao processo de hierarquização: $2^{\circ}$ ) Relevo, Matéria Orgânica e Estrutura (todos com 6 citações); $3^{\circ}$ ) Cor e Textura (com 5 citações), $4^{\circ}$ ) Umidade; $5^{\circ}$ ) Pedregosidade; $6^{\circ}$ ) Litologia, Profundidade e Acidez. Deve-se enfatizar, contudo, que existem termos compartilhados pelos agricultores, ao passo que outros são exclusivos de um ou outro entrevistado, mas devido às inter-relações (laços familiares) e por pertencerem a uma sociedade de interconhecimento (MENDRAS, 1979), muitos termos são tidos como representativos do esquema cognitivo coletivo. 


\section{CONSIDERAÇÕES FINAIS}

A percepção dos elementos paisagísticos testemunham as racionalidades implícitas nos esquemas científico e vernacular, desvendando os ideais e fundamentos próprios de cada saber, que irá imprimir um modo de relacionamento com a natureza: a configuração das paisagens assenta-se sobre formas socialmente construídas de pensar a relação homemnatureza, isto é, reflete os projetos (modernizador e sustentável) e racionalidades (instrumentais e substantivas) às vezes diametralmente opostas, que vão se refletir em última instância em marcas diferentes no espaço.

Assim, a partir da identificação de três sistemas de práticas empreendidos em torno do manejo da biomassa, que está na base da produção orgânica e, portanto, em conformidade com os princípios do manejo ecológico do solo, foi possível construir parâmetros que ajudaram a caracterizar os Terroirs, cujos atributos geoecológicos são valorizados pelos agricultores, pois nestes atributos estão compreendidas suas práticas de paisagem. De modo geral, constatou-se que o aumento da diversidade espacial e temporal ocorre em proporção inversa aos cultivos orgânicos intensivos de olerícolas (mais mercado) e em proporção direta ao aumento da centralidade dos cultivos tradicionais de subsistência (menos mercado).

Dentre as várias constatações, destacamos algumas a seguir. A intensificação da produção nos Terroir A e C (este último em menor intensidade) é beneficiada onde as especificidades geoecológicas regionais configuram ecossistemas propícios ao cultivo das olerícolas: nas depressões ("canhadas") onde ocorre o fenômeno do acúmulo de sedimentos minerais e orgânicos provindos das adjacências (colúvios ou alúvios). No terroir D, as limitações geomorfológicas condicionam algumas práticas de cultivo: cientes dessas limitações, os agricultores deste terroir buscam adaptar seus cultivos de forma a otimizar a produção da biomassa sob o esquema de manejo das populações vegetais que atinge a amplitude dos quatro estágios sucessionais (olerícolas, herbáceas, lavoura, arbóreas). Nesse sentido, busca-se adaptar as práticas agrícolas dentro das limitações de ordem físico-natural.

Contrariamente, o Terroir B que também apresenta limitações geomorfológicas de grau acentuado procura implementar a olericultura orgânica sob os mesmos moldes do terroir A, o que o faz caracterizar como um espaço de produção potencialmente frágil (alta suscetibilidade dos solos à erosão hídrica) do ponto de vista da conservação das qualidades das terras. Nos terroirs onde os solos apresentam-se parcial ou completamente erodidas - fato que 
testemunha os impactos causados durante e após o processo radical de modernização da agricultura - os agricultores têm buscado recuperar a qualidade de suas terras a partir do manejo intensivo da biomassa, segundo esquemas orgânicos de produção ou mesmo da agrofloresta. Mesmo naquelas terras degradadas, desde o ponto de vista de seus atributos físico-morfológicos (nos terroirs B, C e D), os agricultores de base ecológica destacam o fato de que o manejo da biomassa tem lhes permitido recuperar gardativamente a bio-estrutura do solo.

Uma das conclusões do trabalho revela a idéia que a caracterização da dinâmica dos terroirs permitiu-nos constatar que a experiência sobre os limites e potencialidades dos ecossistemas locais está em função da relação que a categoria social dos agricultores familiares agroecológicos estabelece com a natureza. Esta relação, por sua vez, alicerça-se numa base cognitiva que combina racionalidade e subjetividade, isto é, fruto de sua própria história de vida, construídas em interação com a natureza, cuja dinâmica retro-alimenta (informa) o sistema cognitivo, direcionando e adaptando o sistema de práticas agrícolas.

\section{REFERÊNCIAS}

ALMEIDA, J. A Agronomia entre a teoria e a ação. Revista de Educação Agrícola Superior, Brasília, ABEAS, vol. 18. n.2, 2000. pp. 7-13.

BERTRAND, G. La géoagronomie, en nouveau territoire? In: Dir. PREVOST, P. Agronomes et territoires. Actes du colloque. Paris: Edition ENTRETIENS DU PRADEL, p. 25-33, 2005. Paisagem e geografia física global: esboço metodológico. In: Caderno de Ciências da Terra, São Paulo, no. 13, p 1-27,1971.

BERTRAND, C.; BERTRAND, G. Pour une géographie traversière: l'environnement à travers territoires et temporalités. Paris: Éditions Arguments, 2002. 330 p.

BERQUE, A. Paisagem-marca, paisagem-matriz: elementos da problemática para uma geografia cultural. In: CORREA, R.L.; ROSENDAHL, Z. (Org). Paisagem, tempo e cultura. Rio de Janeiro: EdUERJ, 2 ed. 2004, 84-91 p.

BLANC-PAMARD, C. Dialoguer avec le paysage ou comment l'espace écologique est vu et pratiqué par le communautés rurales des hautes terres malgaches. In: Milieux et paysages: essai sur diverses modalités de connaissance. Paris: Mason, 1986, 17-35 p.

CAMARA, G.; SOUZA, RCM; FREITAS, U.M.; GARRIDO, J. SPRING: interacting remote sensing and GIS by object-oriented data modelling. Computers \& Graphics, 20: (3) 395-403, MAY-JUN, 1996. 
CHATELIN, Y; RICHARD, J-F; RIOU, J-F. Du milieu naturel, comme lieu de rencontre du sens comum, de la pensée philosophique et de la démarche scientifique. Milieux et paysages: essai sur diverses modalités de connaissance. Paris: Mason, 1986, 17-35 p. 4-15

CARTIER, S. Terroirs em nuances. In: Revue Strates-LADYSS, n.11, p. 13-26, 2004. Disponível em http://strates.revues.org/index.html . Último acesso 13/09/2006.

CHORLEY, Richard J. A Geomorfologia e a teoria dos sistemas gerais. Notícia Geomorfológica, Campinas, v.11, n.21, 1971, p.3-22.

CLAVAL, P. Épistemologie de la géogrphie. Paris: Armand Colin, 2005, p. 266.

DEFFONTAINES, J-P. Un cheminement entre agronomie et sciences humaines. Palestra proferida no Institute National de Recherche Agronomique (INRA) d'Ivriy, unité Mona, Paris, coordenada por Pierre Alphandéry et Sophie Bobbé, no dia 12 de maio de 2006.

Dynamique physionomique d'un paysage rural. Essai de modélisation de la composante agricole. Paris: Cahiers d'études et de recherches francophones / Agricultures. Volume 4, Numéro 6, Novembre-Décembre, 1995.

FLORIANI, N. Avaliação de terras por agricultores ecológicos de Rio Branco do Sul-PR: uma abordagem geo-sócio-agronômica da paisagem rural. Curitiba, 2007. $308 \mathrm{f}$. Tese (Doutorado Interdisciplinar em Meio Ambiente e Desenvolvimento) -Universidade Federal do Paraná.

GODELIER, M. L'idéel et le matériel: pensée, économies, sociétés. Paris: Librairie Arthème Fayard, 1984. 348 p.

GUMUCHIAN a, H. Les répresentations em géographie. Définitions, méthodes et outils. In: Représenter l'espace. L'imaginaire spatial à l'école. Paris: Anthropos, Diff. Economica, 227 p., 1989.

HOEFFEL, J. L.; FADINI, A. A. B.; MACHADO, M.K. ; REIS, J.C. Percepção Ambiental e Conflitos de Uso dos Recursos Naturais - Um Estudo na APA do Sistema Cantareira, São Paulo, Brasil. In: Campinas: III Encontro ANPPAS, 2006.

KOZEL, S. As representações no geográfico. In: Mendonça, F. et Kozel, S. (Org.). Elementos de Epistemologia da Geografia contemporânea. 20 ed. Curitiba: Editora UFPR, 2002, v. 1, p. 215-232.

LELLI, L. La photographie de paysage comme outil de mobilisation des acteurs por um projet de territoire. In: DEBARBIEUX, B.; LARDON, S. (org.). Les figures du projet territorial. Paris: Auber-datar, 2003. p. 183-191

LEPSCH, I.F; BELLINAZZI Jr., R.; BERTOLINI, D.; ESPÍNDOLA, C.D. Manual para

levantamento utilitário do meio físico e classificação de terras no sistema de capacidade de uso. Campinas: Sociedade Brasileira de Ciência do Solo, $4^{\text {a }}$. ed., 1983, p.161.

LETISSIER, F. Experiénce de cartographie participative à Saint-Denis. In: DEBARBIEUX, B.; LARDON, S. (org.). Les figures du projet territorial. Paris: Auber-datar, 2003. p. 203212.

MENDRAS, H. Sociedades Camponesas. Rio de Janeiro:ed. Zahar, 1978, 268p.

MICHELIN, Y. Des appareils photo jetables au service d'un projet de développement: 
représentations paysagères et stratégies des acteurs locaux de la montagne thiernoise. Cybergeo, Politique, Culture, Représentations, article 65, mis en ligne le 07 décembre 1998, modifié le 15 mai 2007.URL:http://www.cybergeo.eu/index5351.html. Consulté le 25 septembre 2008

RAMALHO FILHO, A.; BEEK, K .J. Sistema de aptidão agrícola das terras. 3 ed. Rio deJaneiro: EMBRAPA-CNPS, 1994.

RoDrigueZ, J. M. M.; SILVA, E. V.; CAVALCANTI, A.P.B. Geoecologia das Paisagens: uma visão geossistêmica da análise ambiental. Fortaleza: ed. UFC, 2007, 222 p.

SAUTTER, G.; PÉLISSIER, P. Pour un atlas des terroirs africains: structure type d'une étude de terroir. L'Homme,vol. IV, janvier-avril, pp. 56-72.

SOTCHAVA, V. B. O estudo de Geossistemas. Revista Métodos em Questão, São Paulo, n.16, p. 1-51, 1977.

SOUSA SANTOS, B. Um discurso sobre as ciências. São Paulo: Ed. Cortez, 3.ed., 2005. 92p.

(Recebido em agosto/08. Aceito em outubro/08) 